\title{
Hvilken hjelp ønsker etterlatte ved selvmord?
}

Ved Kari Dyregrov

\section{"Når du opplever en slik katastrofe, er du ikke i stand til å be noen om noe som helst. Du er fullstendig} fortapt og føler at du vil drukne, og du trenger å bli holdt oppe av noen."

Sitatet er hentet fra mor til en ungdom som hengte seg, og eksemplifiserer det desperate behovet for hjelp og støtte som etterlatte opplever ved selumord. Hvilken type hjelp, fra hvem, og kvaliteter ved hjelpen er undersøkt gjennom Omsorgsprosjektet og forfatterens doktorarbeid ved Senter for Krisepsykologi, Bergen i tidsrommet 1997-2003. I denne artikkelen vil det legges hovedvekt på resultatene fra Omsorgsprosjektet der etterlatte etterspør hjelp fra profesjonelle og sosiale nettverk.

Datamaterialet som er analysert i $0 \mathrm{~m}$ sorgsprosjektet (Dyregrov et al., 1998, 2000a, 2000b) og Doktorgradsprosjektet (Dyregrov, 2002; 2003; 2003-2004; 2004) er i hovedsak det samme. Et par forskjeller skiller dem: M ens O msorgsprosjektet analyserte foreldre og søskens situasjon i tillegg til kommuners hjelpetilbud, avgrenset Doktorprosjektet seg til å fokusere på foreldres situasjon og kommuners tilbud. Sistnevnte prosjekt inkluderte dessuten analyser av et nytt datasett; foreldrenes opplevelser av å delta i sorgforskningen. $M$ ens overlappende data ble analysert ved enkle kvantitative ( frekvens/ korrelasjon) og kvalitative analysemetoder, ble disse og nye data analysert videre ved mer avanserte kvalitative (kon densering/ kategorisering/tematisering) og kvantitative (regresjon/varians/korrelasjon) metoder i Doktorprosjektet. Teoridannelse og teoretisk diskusjon var selvsagt også langt mer sentrale i sistnevnte prosjekt.

\section{Hvilken type hjelp ønskes?}

| 1998-99 deltok 128 foreldre og 70 søsken fra 83 familier som hadde mistet barn/søsken ved selvmord (<30 år) i 0 msorgsprosjektet - en landsdekkende kohortundersøkelse. U ndersøkelsen innhentet kvalitative og kvantitative data for å utforske hvilken type hjelp og støtte etterlatte får fra sosiale nettverk og det offentlige hjelpeapparat, hvordan hjelpen oppleves, og hvilken hjelp etterlatte ønsker seg. Denne artikkelen vil legge hovedvekt på resultatene som gjelder hjel pen etterlatte etterspør fra profesjonelle og sosiale nettverk. I forsøket på å karakterisere noen fellesnevnere på dette området, er det imidlertid nødvendig å presisere at enhver sørgendes situasjon vil være unik og kreve sin særegne tilnærming fra hjelpere og nettverk.

Det er bred enighet blant $88 \%$ av de etterlatte i undersøkelsen om at det ikke er behov for enten formell hjelp (profesjonell/offentlig hjelp) eller uformell støtte (sosiale nettverk) (Dyregrov et al., 2000a, Dyregrov, 2002). Foreldre og søsken hevder at de trenger både profesjonell bistand, nettverksstøtte, og likemannsstøtte (andre etterlatte), ettersom de ulike formene for hjelp dekker ulike behov for hjelp. Dette samsvarer med hva etterlatte forteller på seminarer og samlinger i regi av Landsforeningen for etterlatte ved selvmord (LEVE), samt med den sparsomme internasjonal e forskningen som fins på området (Clark, 2001; M urphy, 2000; Provini et al., 2000). I O msorgsprosjektet er etterlatte mest tilfredse med støtten fra nettverket og andre etterlatte, og minst tilfredse med det profesjonelle hjel peapparatet. $M$ isnøyen mot de profesjonelle retter seg imidlertid i større grad mot at hjelpen er for kortvarig eller uteblir, enn at hjelp som faktisk er blitt mottatt er av dårlig faglig kvalitet.

\section{Profesjonell hjelp}

Svært mange etterlatte uttrykker frustrasjon og bitterhet over det de opplever som forskjellsbehandling når de henviser til den hjelpen som ytes fra hjel peapparatet ved somatisk sykdom eller store katastrofer. I sin nyansering av behovet for profesjonell bistand presiserer etterlatte at de ikke ber om å bli livslange klienter $i$ et behandlingssystem, men at de ønsker hjelp til selvhjelp for best mulig å klare å gå videre i livet. De ber om rutinemessig og hurtig hjelp for å forhindre at de blir klienter over tid. De ønsker tidligst mulig å få hjelp til å forstå hva som skjer, og de ønsker i ulik grad å bli tatt vare på for en tid, enten av sosiale nettverk eller profesjonelle. En stor gruppe etterlatte hevder at mens profesjonelle hjelpere vil være sentrale i noen faser av sorgprosessen, vil sosiale nettverk stå sentralt i langt større deler av den. De sørgende i O msorgsprosjektet ber også kommunene ta ansvar for å mobilisere sosial nettverksstøtte der dette ikke skjer automatisk, og likemannsstøtte via pårørendeforeninger eller gjennom sorg/ støttegrupper.

$M$ ange av undersøkel sens etterlatte gir uttrykk for at de vet at fagfolk og psykososial førstehjelp fins, og at de har rett på hjelp, samtidig som de konstaterer at de har ikke krefter til å be om hjelpen. De ønsker mer eller andre former for profesjonell hjelp enn det de mottar, og de etterspør et system som sikrer automatisk kontakt med offentlige hjelpeteam. De ønsker stabilitet og kontinuitet i støtten, kompetente hjelpere, men samtidig en hjelp som er fleksibel og individuelt tilpasset (Dyregrov, 2002). Det ses klare paralleller mellom disse ønskene for et ideelt oppføl gingstilbud, og det som anbefales i noen få lignende studier ( M urphy, 2000; Provini et al., 2000) eller etterspørres av etterlatte i litteraturen ( W ertheimer, 1999). I det videre utdypes noen av de mest sentrale punktene for den profesjonelle hjelpen som etterspørres.

\section{$\emptyset$ yeblikkelig og utstrekkende hjelp}

D e etterlatte ønsker tidlig og utstrekkende hjelp, som innebærer at de ikke trenger å ta det første initiativet til kontakt. De hevder at de ikke er i stand til å be om den hjelpen de virkelig trenger, selv om hjelpere den første dagen forteller dem at de "må bare ta kontakt dersom de får behov for hjelp". En mor som hadde opplevd først å miste sin eksmann ved selvmord og deretter sin sønn, uttrykte sin desperasjon over at ikke hjel peapparatet hadde tilbudt henne psykososial krisehjelp slik:

Jeg tenkte på hvordan jeg kunne brekke begge beina mine, slik at jeg kunne bli tatt hånd om av noen i hjelpeapparatet. 


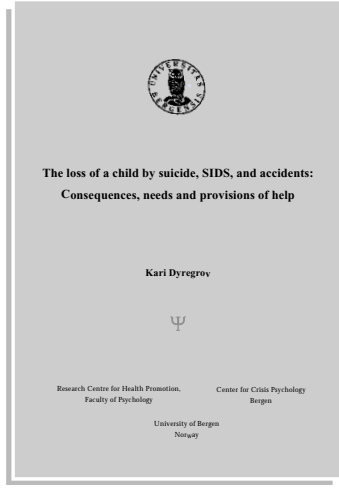

Etterlatte har mange ulike forklaringer på

hvorfor de ikke ber om den hjelpen de hevder å ha sterkt behov for. For det første gjør tap av energi og utmattelse mange sørgende ute av stand til å ta kontakt med hjelpeapparatet. Slik blir, paradoksalt nok, en av de viktigste grunnene til at etterlatte trenger hjelp, en barriere for å få det. Den gjennomgripende stigmatiseringen av selvmord med internalisering av skam og skyld og fordommer fra omgivelsene fører også til at etterlatte nøler med å søke den hjelpen de opplever å trenge. En tredje faktor er at svært mange etterlatte ikke klarer å sette ord på hvilken type hjelp de trenger, eller vet hva som fins av hjel petiltak fra ulike faggrupper. I tråd med funn fra andre studier (Provini et al., 2000) opplevde O msorgsprosjektets etterlatte svært skiftende behov for hjelp gjennom sorgprosessen, og vektla at til bud om hjel p burde gjentas gjennom det første året etter dødsfallet. En etterlatt far foreslo:

$H$ vis kommunehelsetjenesten hadde kontaktet oss og tilbudt oss noen form for regelmessig hjelp etter selvmordet, så kunne jeg ha behandlet denne kontakten som en livbøye, vite at den var der, og bruke den om nødvendig.

\section{Informasjon}

I den første tiden etter selvmordet uttrykker etterlatte et desperat behov for ulike typer informasjon. De etterspør informasjon rundt medisinske aspekt ved dødsfallet, rundt sorgprosessen, samt hvordan dødsfallet kan innvirke på familiemedlemmer og familiesystemet. Spesielt etterspør voksne etterlatte råd for å hjel pe barn som etterlatte, og for å takle kommunikasjonsvansker som oppstår mellom familiemedlemmer og samlivspartnere etter selvmord i familien. De ber om å få informasjon både i muntlig og skriftlig form.

\section{Variert hjelpebehov}

De fleste sørgen de familiene hadde behov for mange ulike former for hjelp i tiden etter selvmordet. Foruten psykopedagogisk informasjon, etterspurte familiene hjelp i forhold til eksistensielle, praktiske, økonomiske, og juridiske spørsmål, så vel som terapeutisk hjelp og råd. Spesielt fremhevet foreldre behovet for

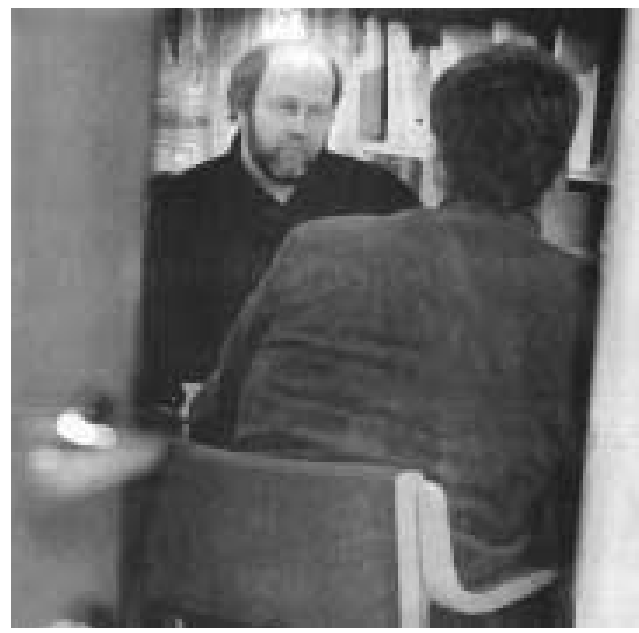

mer spesifikk psykologisk bistand og selvmestringsråd, for å redusere stressreaksjoner, mareritt og flashbacks. $M$ ange visste ikke helt hva de trengte, men uttrykte behov for "psykologhjelp" for seg og sine barn og for familien som system. Den høye forekomsten av foreldre som var i risikosonen for å utvikle komplisert sorg, PT SD, og generelle hel seproblemer (Dyregrov et al., 2003), indikerer at familiene sannsynligvis ville ha profitert på mer slik spesifikk hjelp enn de mottok (Bryant et al., 1998).

\section{H jelp til barn i sorg}

Foreldrene i 0 msorgsprosjektet ba om råd for hvordan de best kan hjel pe barn som etterlatte ved selvmord. H ele 2/3 av foreldrene ønsket mer slik hjelp enn de fikk, og nesten halvparten ( $45 \%$ ) mente at de trengte psykologhjelp til barna. Foreldre ønsket også familierådgivning for å bedre familiedynamikk og for å løse konflikter i foreldre-barn-relasjoner, og for å få støtte og få di skutert egne tanker om best mulig ivaretakelse av barna. Eldre søsken pekte på behovet for mer profesjonell støtte som henvendte seg direkte til dem som sel vstendige individ, og på deres premisser. De sendte en spesiell oppfordring til hjel peapparatet om å hjelpe for-eldre, slik at de selv kunne unngå å påta seg, eller bli belastet med, forel drerollen med ansvar for yngre søsken (Dyregrov, 2001).

\section{H jelp over tid}

Varighet av oppfølging var et sentralt tema, og flesteparten av de etterlatte hevdet at et ideelt hjelpetilbud måtte ha et lengre tidsperspektiv. Spørreskjemaundersøkelsen viste at $73 \%$ ønsket at de hadde blitt tilbudt kontakt med hjel peapparatet over minst ett år. G jennom intervjuene ble ønsket konkretisert som "i minst to år", eller "så lenge som nødvendig", eller "resten av livet". Slike ønsker stod i skarp kontrast til deres erfaringer, som bestod i hjelp den(/de) første uken(e) mens de ennå var i sjokk eller opptatt med planlegging av begravelsen, for så å bli overlatt til den barske virkeligheten. De etterlatte i O msorgsprosjektet påpeker at de sliter med vansker over langt lengre tid en n både hjel peapparatet og sosiale nettverk synes å være klar over (D yregrov, 2002, 2003; Dyregrov et al., 1998, 2000a).

\section{Støtte fra sosiale nettverk}

Betydningen av sosial nettverksstøtte ved traumatiske dødsfall er gjennom tidene beskrevet av ulike sorgforskere ( $D$ unne et al., 1987; Reed, 1998; Sherkat \& Reed, 1992; Thuen, 1997). I O msorgsprosjektet oppgir nesten samtlige foreldre ( $96 \%$ ) og søsken (98\%) at de har mottatt støtte fra venner, familie, naboer, kollegaer på arbeidsplassen eller medelever på skoler. $M$ ens de fleste har behov for støtte fra alle disse gruppene i varierende intensitet over tid, oppgir noen at de bare har behov for støtte fra en mindre gruppe mennesker som de har de sterkeste personlige bånd til. De aller fleste stiller seg likevel bak kvinnen som oppsummerer betydningen av støtten fra sosiale nettverk:

Jeg tror at det at folk viser omsorg og støtte, det er alfa og omega.

I tråd med funn fra den sparsomme forskningslitteraturen på området (Brabant et al., 1995; Dakof \& Taylor, 1990; Thoits, 1995; W ertheimer, 1999) viste O msorgsprosjektet at nettverksstøtten også, av ulike grunner, kunne være utilstrekkelig eller til og med skadelig, og således resultere i det motsatte av intensjonen (Dyregrov, 2003-2004). Det som etterlatte definerte som "ideell støtte" var identisk med støtte de hadde opplevd som "hjelpsom", mens "ikke hjelpsom søtte" representerte motsatsen til kontakt som var mest savnet eller belastende.

\section{H jelpsom stotte}

$\checkmark$ år forskning bekrefter at sørgende mottar til dels massiv støtte fra familie, venner, arbeidskollegaer, naboer medelever på skole etc., spesielt i løpet av de første 


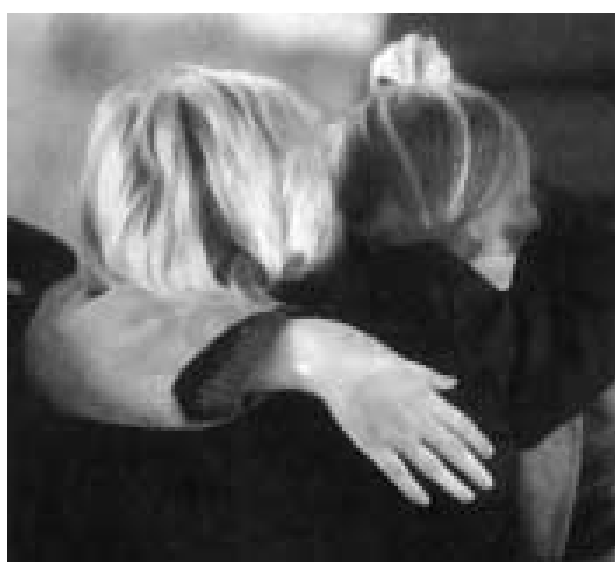

ukene etter dødsfallet. A It dette ble høyt verdsatt av de etterlatte (Dyregrov, 20032004; Dyregrov et al., 2000a). Først og fremst har de fleste fått "et hav av blomsterhilsener" både til hjemmet og ved begravel sen. Blomster har kommet fra familie, fra nære og fjerne bekjente, fra arbeidsplass og foreninger og fra familiene til avdødes venner. Familie, naboer og venner har tatt kontakt ved å komme til hjemmet, ringe eller skrive til dem. Gode venner og nær familie har stilt opp døgnet rundt. $\mathrm{N}$ oen har brakt bøker eller dikt for å uttrykke sin medfølelse, eller for å gi dem informasjon for å gi støtte for fremtiden. A ndre har fysisk holdt rundt de etterlatte de første døgnene. De har kommet tidlig om morgenen og vært hos de etterlatte til de la seg og hjulpet dem til å eksistere de første uvirkelige døgnene. N oen venner har også ligget over hos de etterlatte de første nettene for å kunne snakke med dem når de ikke fikk sove. De etterlatte har fått gråte og uttrykke sin fortvilelse sammen med venner og familie, som har trøstet dem så godt de har kunnet. De har fătt stille spørsmålet "hvorfor skjedde det?", om og om igjen. N ære venner fikk ofte den vanskelige oppgaven å lete etter svar sammen med de etterlatte, og opplevde å komme til kort, fordi det ikke fantes svar. Etter de første og mest uvirkelige ukene der de etterlatte strev de for å holde seg oppegåen de rent fysisk, har mange etterlatte verdsatt at venner, naboer eller arbeidskollegaer forsøkte å få dem tilbake til en mer normal hverdag. N ettverket har ringt og oppmuntret etterlatte til sosiale aktiviteter, eller bare kommet på døren for å ta dem med ut på tur når initiativ og livslyst var fraværende. A ndre nettverksmedlemmer har fulgt etterlatte til gravplassen, bedt dem hjem til seg, eller hjulpet dem tilbake til arbeid.

Selv om de aller fleste etterlatte opplever en enorm oppmerksomhet de første døgnene, er det stor enighet om at det er vanskelig å få for mye oppmerksomhet. Selv om oppslutningen i begynnelsen kan oppleves både slitsom og overveldende når den står på, så uttrykker etterlatte at de likevel ikke ville ha unnvært det; jfr. en far:

D et var veldig godt at det kom så mange. D et blir aldri for mange. D et er mange som tenker at det blir... men det blir aldri for mange.

\section{M est savnet}

Til tross for alle de positive erfaringene, opplevde undersøkel sens etterlatte også savn ved eksisteren de støtte, uteblivelse av forventet støtte, eller negative møter med medlemmer i det sosiale nettverket (Dyregrov et al., 2000a; Dyregrov, 20032004).

Selv om etterlatte over tid ikke forventer eller føler behov for like sterk omsorg som like etter dødsfallet, ønsker svært mange etterlatte at omgivel sene skulle forstått mer av etterlattes reaksjoner og sorgprosessens lengde og intensitet (Dyregrov, 2003-2004; M urphy, 2000;

W ertheimer, 1999). Etterlatte forteller at første uken er nærmeste familie og venner i kontakt med familien mange ganger i døgnet. M er perifere naboer, venner og familie tar kontakt kanskje et par ganger og mange lar det bli med det. De fleste etterlatte opplever at hyppigheten av å bli kontaktet synker kraftig etter begravelsen, men at "folk flest" likevel husker på dem ca. et halvt års tid. Etter denne tid, er det svært mange etterlatte som er skuffet over at venner og omgangskrets "synes å glemme det som har skjedd så fort". Etterlatte savner at de i naturlige settinger spør hvordan det går, stikker innom, og snakker om eller nevner avdødes navn. De som fortsatt oppfyller slike behov når det er gått ett eller to år, er noen ytterst få venner og familiemedlemmer som har vært, eller er blitt, nære fortrolige. Etterlatte forteller at slike "nære fortrolige" betyr svært mye for at de "overlever" fordi de "kan komme til dem når som helst og snakke om hva som helst". En del etterlatte peker selv på at ved større åpenhet i kommunikasjonen om selvmordet, hvordan de har det, og hvilken hjelp og støtte de har behov for, ville nettverket bedre ha kunnet støtte den enkelte og dennes familie på deres særskilte premisser. De peker også på hvorfor dette er vanskelig å få til (Dyregrov, 2003-2004).

\section{$M$ est belastende}

Svært mange etterlatte har erfaringer med at mennesker de forventet at ville støtte, unngår dem "ved å krysse gaten", eller på andre måter lar være å ta kontakt. Dette oppleves som en belastning. I $0 \mathrm{~m}$ sorgsprosjektet oppgir foreldre (39\%) og søsken $(41 \%)$ at de savner støtte/mer støtte fra en eller flere i sitt sosiale nettverk. M ens $23 \%$ av foreldrene savner støtte fra familiemedlemmer, er det bare $12 \%$ som etterlyser støtte fra venner. At famili emedlemmer synes å skuffe etterlatte dobbelt så ofte som venner kan bl.a. ha med høyere forventninger mht. innhold og omfang av støtte til førstnevnte, og/eller at familiemedlemmer i mindre grad klarer å støtte de nærmeste etterlatte fordi de selv er rammet av tapet (Brabant et al., 1995; Lehman et al., 1986). M ange av disse forventningene medførte skuffelser for de etterlatte (Dyregrov, 20032004). Som andre også har pekt på synes dette å være skuffelser som kan knyttes til kommunikative og relasjonelle forhold mellom etterlatte og nettverket ( $\mathrm{H}$ arris, 1992; Thompson \& Range, 1992; W ertheimer, 1999).

\section{Etterlattes råd}

Til tross for mange skuffelser i møte med sosiale nettverk så vel som fremmede, presiserte mange etterlatte at de langt på vei unnskyldte nettverket. De opplev de at såren de bemerkninger eller unngåel se oftest ikke var ment å såre, men heller uttrykte en utilstrekkelighet i å yte støtten de trengte. A vslutningsvis oppsummeres derfor råd til det offentlige hjelpeapparat, sosiale nettverk og andre etterlatte fra O msorgsprosjektets etterlatte for hvordan de ønsket å bli møtt etter selvmord i nær familie (se neste side). 


\section{Etterlattes råd til offentlig hjelpeapparat}

- Ta kontakt - tilby hjelp, ikke overlat initiativet til oss.

- Organiser dere og lag rutiner, ikke la hjelp bli tilfeldig.

- Fordel dere, ikke kom alle på en gang - og ikke bare i starten.

- Vaer der også når hverdagen kommer.

- Vaer fleksible, lytt til hva vi trenger, men ta over når det trengs.

- Hjelp oss til å ta farvel på en best mulig måte.

- Informer oss om:

- hvordan dødsfallet skjedde

- hva som skal skje videre

- hvor og av hvem vi kan få hjelp

- sorg- og krisereaksjoner

- hvordan menn, kvinner og barn reagerer forskjellig.

- Hjelp oss i kontakt med psykolog og andre nødvendige faggrupper.

- Hjelp barna våre, og/eller hjelp oss til å hjelpe dem.

- Ikke glem andre utenfor naermeste familie som er hardt rammet.

- Hjelp oss i kontakt med andre som har opplevd det samme.

- Gjenta tilbud om hjelp over tid.

- Vaer der i minst et år, eller så lenge vi trenger dere.

\section{Etterlattes råd til sosiale nettverk}

- Ikke trekk dere unna - tørr å vaere naer.

- Det er ikke alltid så viktig å si så mye, bare vis at dere bryr dere.

- Praktisk hjelp, f.eks. avlastning med barn kan vaere uvurderlig.

- Vis respekt og tålmodighet for vår måte å sørge på.

- Gi kontakt og støtte over tid.

- Glem aldri den vi mistet.

\section{Etterlattes råd til andre etterlatte}

- Vaer åpne om hvordan dere har det.

- Bearbeid sorgen ved å snakke om det som har hendt.

- La andre se at dere tåler og ønsker åpenhet.

- Forklar andre hvordan dere ønsker hjelp og støtte.

- Ta imot hjelp og støtte.

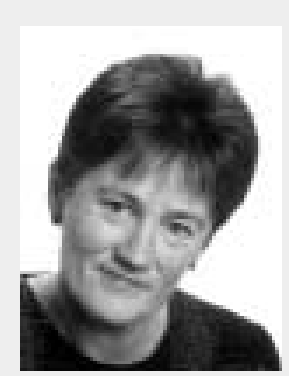

Kari D yregrov er sosiolog, dr. philos, og arbeidet som fysioterapeut innen ulike deler av helsevesenet før hun avsluttet hovedfag i sosiologi ved U niversitetet $\mathrm{i}$ Bergen i 1995. Siden da har hun vært ansatt som forsker ved Senter for Krisepsykologi (SfK), Bergen, og gjennomført mange forskningsprosjekt knyttet til selvmord, etterlatteproblematikk, sorg og kriser. Etter avsl uttet doktorarbeid i 2003 ble hun forskningsleder ved SfK. H un har vært Landsstyremedlem i LEVE siden 1999 og har hatt en sentral rolle i etableringen og oppbyggingen av organisasjonen.

\section{Referanser}

Brabant, S., Forsyth, C., \& M cFarlain, G . (1995). Life after the death of a child: initial and long term support from others. 0 mega, 31, 67-85.

Bryant, R. A ., H arvey, A . G ., Dang, S. T., \& Sackville, T. (1998). Treatment of acute stress disorder: A comparison of cognitive-behavioral therapy and supportive counselling. Journal of Consulting and Clinical Psychology, 66, 5, 862866.

Clark, S. E. (2001). B ereavement after suicide: Mountains, Milestones and the $\mathrm{N}$ ew Millennium -W here to now? A report of Forum at the

$7^{\text {th }} \mathrm{N}$ ational C onference of Suicide Prevention, A ustralia. M el bourne.

Dakof, G. A ., \& Taylor, S. E. (1990). Victims' perceptions of social support: W hat is helpful from whom? Journal of Personality and Social Psychology, 58, 80-89.

Dunne, E. J., M clntosh, J. L., \& Dunne-M axim, K. (Eds.) (1987). Suicide and its aftermath: U nderstanding and counselling the survivors. $\mathrm{N}$ ew York: N orton.

Dyregrov, K. (2001). Søsken etter selvmord I: A. Dyregrov, G. Lorentzen, \& K. Raaheim (red.), Et liv for barn. U tfordringer, omsorg og hjel petiltak. Fagbokforlaget (s.146-158). Bergen.

Dyregrov, K. (2002). A ssistance from local authorities versus survivors' needs for support after suicide. D eath Studies, 26, 647-669.

Dyregrov, K. (2003). The loss of a child by suicide, SID S, and accidents; C onsequences, needs and provision of help. D octoral Dissertation (Dr. Philos), Faculty of Psychology, HEM IL U niversity of B ergen. N orway.

Dyregrov, K. (2003-2004). Micro-sociological analysis of social support following traumatic bereavement: $U$ nhelpful and avoidant responses from the community. OM EG A - Journal of D eath and Dying, 48, 1, 23-44.
Dyregrov, K. (2004). Strategies of professional assistance after traumatic deaths: Empowerment or disempowerment? Scandinavian Journal of Psychology, 45,179-87.

Dyregrov, K, N ordanger, D., \& Dyregrov, A (1998). O msorg for etterlatte etter selvmord. Kommunestudien. Rapport. Senter for Krisepsykologi. Bergen.

Dyregrov, K, N ordanger, D., \& Dyregrov, A (2000a). 0 msorg for etterlatte ved selvmord. Etterlattestudien. Rapport. Senter for K risepsykologi. Bergen.

Dyregrov, K, N ordanger, D., \& Dyregrov, A (2000b). 0 msorg for etterlatte ved brå, uventet død. Evaluering av behov, tilbud og tiltak. Rapport. Senter for K risepsykologi. Bergen.

Dyregrov, K., N ordanger, D., \& Dyregrov, A . (2003). Predictors of psychosocial D istress after suicide, SID S, and accidents. Death studies, 27, 143-165.

Harris, T. O . (1992). Some reflections on the process of social support and the nature of unsupportive behaviors. In $\mathrm{H}$. O. F. Veiel $\& U$. Baumann (eds.), The meaning and measurement of social support (pp. 171-190). N ew York: Hemisphere.

Lehman, D. R., Ellard, J. H ., \& W ortman, C. B. (1986). Social support for the bereaved: Recipients' and providers' perspective on what is helpful. Journal of $C$ onsulting and C linical Psychology, 54, 438-445.

M urphy, S. A . (2000). T he use of research findings in bereavement programs: A case study. D eath Studies, 24, 585-602.

Provini, C., Everett, J. R., \& Pfeffer, C. R. (2000). A dults mourning suicide: Self-reported concerns about bereavement, needs for assistance, and help-seeking behavior. D eath Studies, 24, 1-9.

Reed, M . D. (1998). Predicting grief symptomatology among the suddenly bereaved. Suicide and Life-T hreatening Behavior, 28, 3, 285-300.

Sherkat, D. E., \& Reed, M. D. (1992). T he effects of religion and social support on self-esteem and depression among the suddenly bereaved. Social Indicators Research, 26, 259-275.

Thoits, P. A . (1995). Stress, coping, and social support processes: W here are we? What next? Journal of $\mathrm{H}$ ealth and Social Behavior, (Extra issue), 53-79.

Thompson, K. E., \& Range, L. M. (1992)

Bereavement following suicide and other deaths. W hy support attempts fail. Part of first authors Doctoral dissertation.

Thuen, F. (1997). R eceived social support from informal networks and professionals in bereavement. Psychology, $\mathrm{H}$ ealth \& M edicine, 2,1 ,

51-59.

Wertheimer, A . (1999). A special scar.

$T$ he experiences of people bereaved by suicide $\left(5^{\text {th }}\right.$ ed.). London: Routledge. 